\title{
Prevalence of Chronic Pain, Especially Headache, and Relationship with Health-Related Quality of Life in Middle-Aged Japanese Residents
}

\author{
Junko Mitoma1, Masami Kitaoka1, Hiroki Asakura1, Enoch Olando Anyenda1, \\ Daisuke Hori ${ }^{1}$, Nguyen Thi Thu Tao ${ }^{1}$, Toshio Hamagishi ${ }^{1}$, Koichiro Hayashi', \\ Fumihiko Suzuki', Yukari Shimizu1, Hiromasa Tsujiguchi', Yasuhiro Kambayashi', \\ Yuri Hibino1, Tadashi Konoshita' ${ }^{2}$, Takiko Sagara1', Aki Shibata1, Hiroyuki Nakamura1 \\ ${ }^{1}$ Department of Environmental and Preventive Medicine, Graduate School of Medical Science, \\ Kanazawa University, Ishikawa, Japan \\ ${ }^{2}$ Third Department of Internal Medicine, Fukui University School of Medicine, Fukui, Japan \\ Email: mitoma@stu.kanazawa-u.ac.jp
}

Received 15 December 2015; accepted 24 January 2016; published 27 January 2016

Copyright (C) 2016 by authors and Scientific Research Publishing Inc.

This work is licensed under the Creative Commons Attribution-NonCommercial International License (CC BY-NC).

http://creativecommons.org/licenses/by-nc/4.0/

(c) (i) (8) Open Access

\section{Abstract}

The aim of this study was to evaluate the prevalence of chronic pain (CP) and the relationship between $\mathrm{CP}$, especially headache adjusted for $\mathrm{CP}$ at other sites, and health-related quality of life (HRQOL) in middle-aged Japanese residents. We examined the prevalence of CP (defined as pain persisting for 3 months or more) and HRQoL (SF-36) in 1117 middle-aged residents of Japan. We assessed the eight dimensions of health status and the 3 component SF-36 summary score to evaluate HRQoL. The prevalence of CP was $15.3 \%$ among men and $15.1 \%$ among women. Multiple linear regression analysis demonstrated that lumbar pain $(p<0.001, \beta=-0.132)$, knee pain $(p<$ $0.001, \beta=-0.115)$, foot pain $(p=0.042, \beta=-0.065)$, and age $(p<0.001, \beta=-0.154)$ were independently correlated with a lower physical component score (PCS). Older age $(p<0.001, \beta=0.221)$ showed a significant positive correlation with mental component score (MCS), while neck/shoulder pain $(p<0.01, \beta=-0.096)$, knee pain $(p<0.001, \beta=-0.109)$, upper limb pain $(p<0.01, \beta=$ -0.098), and lumbar pain $(p=0.022, \beta=-0.077)$ all showed a significant negative correlation with MCS. The presence of chronic headache $(p=0.011, \beta=-0.082)$ was the only factor significantly correlated with a lower role component score (RCS). We identified a negative correlation between chronic headache and RCS, unlike the relation between musculoskeletal pain and PCS or MCS, suggesting that RCS was an independently influenced by CP differently from PCS or MCS in Japanese residents. 


\section{Keywords}

\section{Quality of Life, Chronic Pain, Headache, SF-36, Pain}

\section{Introduction}

The International Association for the Study of Pain (IASP) defines pain as an unpleasant sensory and emotional experience associated with actual or potential tissue damage, or described in terms of such damage [1]. In addition, the IASP defines chronic pain (CP) as pain without an apparent biological cause that persists beyond the normal time for tissue healing (usually 3 months) [2].

Some of the previous studies have been hospital-based [3] or focused on the elderly persons [4], and few studies have investigated CP in the general Japanese population. In a telephone survey study, among the general population in European countries and Israel shows a variation in prevalence of CP that ranges from $12 \%$ to $30 \%$ depending on the geographical area and age [5]. Previous survey shows that $9 \%$ to $28 \%$ of the Japanese population have $\mathrm{CP}$, and that it is less frequent in people under 40 years old than in other age groups, whereas it appears to be higher in the 41 - 60 age group than in the others [6] [7]. Also there is a higher prevalence among elderly persons and in women [6]-[8]. A study performed in Japan reports aging as part of reason for increase of persons suffering from CP, however, it still remains unclear [9]. CP is usually musculoskeletal pain, such as lumbar pain, shoulder pain, or knee pain [6]-[8]. It is common for people with CP to be on long-term therapy and to be dissatisfied with their current treatment [10].

CP causes deterioration of HRQoL because it not only affects the physical condition and ability to function, but also the person's mental health and daily activities [7], which can lead to exacerbation of symptoms. CP restricts the ability to work and is responsible for substantial health care costs, resulting in it being a major public health problem worldwide [5]. Considering that the health effects of CP are multi-dimensional, it is important to elucidate the involvement of physical, mental, and social factors, as well as how role factors are related to CP.

Among the various body sites affected by $\mathrm{CP}$, headache is reported to cause marked impairment of daily activities, such as family and social activities [11]. Chronic headache results in substantially greater disability than other types of headache [12], and is often combined with other chronic pain disorders [13]. To measure the disability caused by headache itself, we need to adjust for the impact of chronic pain at other sites. Therefore, we examine the prevalence of both headache and CP at other sites, as well as the impact on HRQoL, in middleaged Japanese residents.

\section{Methods}

\subsection{Subjects and Methods}

We performed this study from October to December 2012. The target population was all of the middle-aged persons legally residing in the two elementary school districts in a rural area (Shika, Isikawa prefecture). This study was supported by the Shika Municipal Government, which provided a list of all residents aged 40 to 65 years in this area. The eligible population was 1291 persons and almost all of them were Japanese citizens.

We provided self-administered questionnaire to the residents. After they filled in the answers, participants were asked to return the questionnaires in sealed envelopes to members of the health promotion team employed by Shika Municipal Government.

The self-administered questionnaire was designed to obtain demographic data such as the age, gender, height and weight, as well as self-reported information on medical conditions such as cerebrovascular disease, cardiovascular disease, hypertension, dyslipidemia, diabetes mellitus, history of fracture over 10 years, osteoarthritis, depression, osteoporosis, insomnia, rheumatoid arthritis, CP at up to 3 sites, and HRQoL.

We asked the subjects to rate the severity of $\mathrm{CP}$ on a 10 -point scale $(0=$ no pain to $10=$ most severe pain ever experienced). We defined CP as pain persisting for 3 months or longer (in agreement with the IASP) at a severity of more than 5 so that we could compare our data with other surveys performed in Europe and Japan [5] [6]. We asked about the presence of pain affecting the head, neck, shoulder, upper limb, back, lumbar, hip, knee, foot, chest, and abdomen. We classified the site of pain as follows: head, neck/shoulder, upper limb, lumbar re- 
gion, hip, knee, foot, and other (including back, hip, chest, and abdomen).

To measure HRQoL, we used the SF-36, Japanese version 2. The SF-36 is used worldwide to measure HRQoL, especially in general populations. It has been translated into Japanese and validated for use in Japan [14]. SF-36 measures eight dimensions of health over four weeks, which are physical functioning (PF), role physical (RP), bodily pain (BP), general health (GH), vitality (VT), social function (SF), role emotional (RE), and mental health (MH). We used a norm-based scoring (NBS) system, in which all scores were converted to the values relative to the Japanese population (mean $=50$ and standard deviation $=10$ with a normal distribution; higher scores indicate better HRQoL) [15]. These eight scores were further summarized into three component summary scores, which were the physical component summary (PCS), mental component summary (MCS), and role component summary (RCS). The factor structures of SF-36 reported in Japan [16], China [17] [18], Taiwan [19], and Singapore [20] are considered to differ from those found in western countries [21]. A previous study on validation of component models supported a three-component model as superior to a two-component model in Japan [22]. A three-component model was demonstrated to provide "purer" factor-loading patterns in the physical and mental components, with the mental component showing greater improvement [22]. Therefore, we employed a three-component model in this study.

\subsection{Statistics}

We used the unpaired t-test and analysis of variance (ANOVA) for continuous data. The chi-square test was employed for categorical data, except when the expected number of cells was less than 5 in which case we used Fisher's exact test. We used analysis of covariance (ANCOVA) for continuous data adjusted for age and gender. Multiple linear regression analysis was performed with a forward stepwise approach to estimate the impact of each variable on the component summary scores. The independent variables assessed included the age, gender (male 0 , female 1 ), and each site of pain (no pain 0 , with pain 1 ). All tests were 2-tailed, with differences reported as significant at $p<0.05$. Analyses were conducted using IBM SPSS Statistics version19 for Windows.

\subsection{Study Protocol Approval and Consent}

This study was conducted with the approval of the ethics review board of Kanazawa University (Kanazawa, Japan). All participants provided written informed consent by signing a form that described the purpose and procedures of the study, the potential risks and benefits associated with participation, the strictly voluntary nature of participation, the right to withdraw from the study without prejudice or penalty, and the guaranteed confidentiality and security of personal data.

\section{Results}

We excluded persons who did not give consent $(n=111)$, who could not be contacted $(n=52)$, and who were hospitalized or institutionalized $(\mathrm{n}=11)$ from the 1291 residents, and obtained responses from 1117 people (86.0\%; 556 men and 561 women, mean age: $54.7 \pm 7.73$ in male, $54.7 \pm 7.66$ in female).

The prevalence of CP was $15.3 \%$ among men and $15.1 \%$ among women. In the male subjects, the site of pain (in decreasing order) was neck/shoulder pain in 6.86\%, lumbar pain in $6.69 \%$, foot pain in $3.43 \%$, knee pain in $2.88 \%$, upper limb pain in $1.98 \%$, and headache in $0.899 \%$, while the site of pain in the female subjects was neck/shoulder pain in $7.16 \%$, lumbar pain in $5.92 \%$, knee pain in $3.58 \%$, foot pain in $2.85 \%$, upper limb pain in $1.96 \%$, and headache in $1.43 \%$. There was one site of CP in $8.76 \%$ of male subjects and $7.94 \%$ of female subjects, two sites in $4.20 \%$ and $4.69 \%$, and three sites in $2.92 \%$ and $2.71 \%$ (Table 1 ).

While VT, MH, and MCS were significantly higher, PCS was lower in the older subjects compared with the younger subjects among both males and females. PF was significantly lower in older subjects compared with younger subjects among females only (Table 2).

ANCOVA with covariates of age and gender showed that PF, RP, BP, GH, VT, SF, RE, MH, PCS, and MCS were all significantly lower in the subjects with CP compared to those without CP. Only RCS showed no significant difference between subjects with and without CP (Table 3).

To evaluate the impact of pain at different sites on HRQoL, we performed stratified analysis by pain site. The subjects with CP affecting the neck/shoulder, lumbar, knee, foot, and other sites had a significantly lower PCS than those without CP. In subjects with CP at all sites, MCS was significantly lower than in those without CP. In subjects with chronic headache, RCS was significantly lower than in those without CP (Table 4). 
Table 1. Characteristics of the participants $(\mathrm{N}=1117)$.

\begin{tabular}{|c|c|c|c|}
\hline Gender & Male $(n=556)$ & Female $(n=561)$ & $P$ value \\
\hline Age: mean (SD) & $54.7(7.73)$ & $54.7(7.66)$ & 0.340 \\
\hline Height (cm): mean (SD) & $168.8(6.14)$ & $155.4(5.49)$ & 0.018 \\
\hline Weight (kg): mean (SD) & $67.8(10.4)$ & $54.4(8.01)$ & $<0.001$ \\
\hline BMI: mean (SD) & $23.8(3.12)$ & $22.6(3.25)$ & 0.246 \\
\hline \multicolumn{4}{|l|}{ Diseases } \\
\hline Cerebrovascular disease (\%) & 1.80 & 0.535 & 0.055 \\
\hline Cardiovascular disease (\%) & 2.70 & 1.60 & 0.208 \\
\hline Hypertension (\%) & 22.5 & 19.3 & 0.184 \\
\hline Dyslipidemia (\%) & 10.4 & 16.4 & $<0.01$ \\
\hline Diabetes mellitus (\%) & 10.3 & 5.35 & $<0.01$ \\
\hline Fracture within 10 years (\%) & 4.86 & 3.39 & 0.217 \\
\hline Osteoarthritis (\%) & 1.80 & 3.39 & 0.095 \\
\hline Depression (\%) & 1.62 & 1.96 & 0.666 \\
\hline Osteoporosis (\%) & 0.540 & 2.14 & 0.034 \\
\hline Insomnia (\%) & 1.44 & 1.60 & 0.821 \\
\hline Rheumatoid arthritis (\%) & 0.719 & 0.891 & 1.000 \\
\hline \multicolumn{4}{|l|}{ Prevalence of pain } \\
\hline Any (\%) & 15.3 & 15.1 & 0.919 \\
\hline Head (\%) & 0.899 & 1.43 & 0.412 \\
\hline Upper-limb (\%) & 1.98 & 1.96 & 0.980 \\
\hline Neck/Shoulder (\%) & 6.86 & 7.16 & 0.846 \\
\hline Lumbar (\%) & 6.69 & 5.92 & 0.600 \\
\hline Knee (\%) & 2.88 & 3.58 & 0.508 \\
\hline Foot (\%) & 3.43 & 2.85 & 0.580 \\
\hline Others (\%) & 2.89 & 2.32 & 0.553 \\
\hline \multicolumn{4}{|l|}{ Number of chronic pain site } \\
\hline One site (\%) & 8.76 & 7.94 & 0.935 \\
\hline Two sites (\%) & 4.20 & 4.69 & \\
\hline Three sites (\%) & 2.92 & 2.71 & \\
\hline \multicolumn{4}{|l|}{ SF-36 score } \\
\hline PF: mean (SD) & $49.9(11.0)$ & 49.5 (9.97) & 0.306 \\
\hline RP: mean (SD) & $51.2(9.22)$ & $50.6(9.29)$ & 0.397 \\
\hline BP: mean (SD) & $49.9(10.7)$ & $50.3(10.2)$ & 0.536 \\
\hline GH: mean (SD) & $48.0(9.04)$ & $48.4(9.24)$ & 0.481 \\
\hline VT: mean (SD) & $50.3(10.2)$ & $50.1(10.1)$ & 0.907 \\
\hline SF: mean (SD) & $51.5(9.23)$ & $50.7(9.56)$ & 0.157 \\
\hline RE: mean (SD) & $51.8(8.93)$ & $50.7(9.34)$ & 0.026 \\
\hline MH: mean (SD) & $50.3(9.31)$ & $50.3(9.52)$ & 0.191 \\
\hline PCS: mean (SD) & $48.5(10.6)$ & $49.0(9.96)$ & 0.684 \\
\hline MCS: mean (SD) & $49.1(9.74)$ & $49.6(9.80)$ & 0.659 \\
\hline RCS: mean (SD) & $53.0(10.1)$ & $51.8(10.1)$ & 0.376 \\
\hline
\end{tabular}

SD: Standard Deviation; PF: Physical Functioning; RP: Role Physical; BP: Bodily Pain; GH: General Health; VT: Vitality; SF: Social Function; RE: Role Emotional; MH: Mental Health; PCS: Physical Component Summary; MCS: Mental Component Summary; RCS: Role Component Summary; Others include chest, abdomen, hip, and back pain. We used the unpaired t-test for continuous data and the $\chi^{2}$ test for categorical data. 
Table 2. SF-36 scores of subjects in each age group.

\begin{tabular}{|c|c|c|c|c|c|c|c|c|c|c|c|c|c|c|c|c|c|c|c|}
\hline & \multicolumn{10}{|c|}{ Male } & \multicolumn{9}{|c|}{ Female } \\
\hline & \multicolumn{3}{|c|}{$40-49$} & \multicolumn{3}{|c|}{$50-59$} & \multicolumn{3}{|c|}{$60-65$} & \multirow{2}{*}{$P$ value } & \multicolumn{3}{|c|}{$40-49$} & \multicolumn{3}{|c|}{$50-59$} & \multicolumn{2}{|r|}{$60-65$} & \multirow{2}{*}{$P$ value } \\
\hline & $\mathrm{N}$ & Mean & SD & $\mathrm{N}$ & Mean & SD & $\mathrm{N}$ & Mean & SD & & $\mathrm{N}$ & Mean & SD & $\mathrm{N}$ & Mean & $\mathrm{SD}$ & $\mathrm{N}$ & Mean SD & \\
\hline $\mathrm{PF}$ & 136 & 50.3 & (12.9) & 164 & 50.8 & (8.23) & 179 & 48.9 & (11.5) & 0.272 & 140 & 51.5 & (8.75) & 195 & 49.6 & (8.95) & 178 & 47.9 (11.6) & $<0.01$ \\
\hline $\mathrm{RP}$ & 135 & 52.0 & (8.93) & 163 & 51.1 & (8.24) & 179 & 50.6 & $(10.2)$ & 0.410 & 141 & 51.8 & (8.79) & 193 & 50.8 & (8.90) & 177 & 49.4 (9.98) & 0.061 \\
\hline BP & 136 & 49.4 & $(10.8)$ & 164 & 50.3 & (11.0) & 180 & 49.8 & (10.5) & 0.767 & 142 & 50.3 & $(9.42)$ & 195 & 50.1 & (10.7) & 178 & 50.6 & 0.899 \\
\hline $\mathrm{GH}$ & 136 & 48.2 & (8.38) & 164 & 47.2 & (9.33) & 178 & 48.6 & (9.25) & 0.311 & 141 & 48.8 & $(8.81)$ & 193 & 47.7 & (9.77) & 177 & 48.8 (8.97) & 0.447 \\
\hline VT & 136 & 48.4 & $(10.2)$ & 164 & 48.9 & $(9.80)$ & 177 & 53.1 & (9.91) & $<0.001$ & 141 & 47.6 & $(9.80)$ & 194 & 49.4 & $(10.2)$ & 176 & 53.0 & $<0.001$ \\
\hline SF & 136 & 51.4 & (8.65) & 163 & 51.2 & (8.86) & 180 & 51.8 & $(10.0)$ & 0.858 & 142 & 49.5 & $(10.8)$ & 193 & 50.7 & (9.68) & 178 & 51.5 & 0.182 \\
\hline $\mathrm{RE}$ & 135 & 52.5 & $(8.27)$ & 162 & 51.2 & (8.96) & 179 & 51.8 & (9.37) & 0.439 & 141 & 50.9 & $(9.51)$ & 193 & 50.7 & (9.34) & 176 & $50.6(9.27)$ & 0.955 \\
\hline $\mathrm{MH}$ & 136 & 48.6 & (8.88) & 164 & 49.3 & $(9.48)$ & 177 & 52.5 & (9.09) & $<0.001$ & 141 & 48.4 & $(10.2)$ & 192 & 50.2 & (9.18) & 176 & 51.9 (9.04) & $<0.01$ \\
\hline PCS & 134 & 49.7 & $(12.2)$ & 161 & 49.6 & (8.14) & 176 & 46.7 & (11.1) & 0.018 & 140 & 51.7 & (8.69) & 188 & 48.9 & (9.39) & 173 & $47.0(11.0)$ & $<0.001$ \\
\hline MCS & 134 & 47.0 & (9.39) & 161 & 47.6 & (9.72) & 176 & 52.0 & (9.36) & $<0.001$ & 140 & 47.0 & $(9.54)$ & 188 & 48.9 & (10.3) & 173 & 52.4 (8.74) & $<0.001$ \\
\hline RCS & 134 & 53.9 & $(9.26)$ & 161 & 52.5 & (10.1) & 176 & 52.8 & (10.7) & 0.439 & 140 & 51.6 & (11.4) & 188 & 52.3 & (9.63) & 173 & 51.4 (9.59) & 0.676 \\
\hline
\end{tabular}

SD: Standard Deviation; PF: Physical Functioning; RP: Role Physical; BP: Bodily Pain; GH: General Health; VT: Vitality; SF: Social Function; RE: Role Emotional; MH: Mental Health; PCS: Physical Component Summary; MCS: Mental Component Summary; RCS: Role Component Summary; ANOVA was employed for categorical data.

Table 3. SF-36 scores of participants with or without chronic pain.

\begin{tabular}{|c|c|c|c|c|c|c|c|}
\hline & \multicolumn{3}{|c|}{ With chronic pain } & \multicolumn{3}{|c|}{ Without chronic pain } & \multirow{2}{*}{$P$ value } \\
\hline & $\mathrm{N}$ & Mean & SD & $\mathrm{N}$ & Mean & SD & \\
\hline PF & 150 & 44.9 & 12.4 & 831 & 50.6 & 9.72 & $<0.001$ \\
\hline $\mathrm{RP}$ & 149 & 45.4 & 12.6 & 828 & 51.8 & 8.17 & $<0.001$ \\
\hline BP & 150 & 38.8 & 9.43 & 834 & 52.2 & 9.22 & $<0.001$ \\
\hline $\mathrm{GH}$ & 150 & 42.2 & 8.89 & 828 & 49.3 & 8.79 & $<0.001$ \\
\hline $\mathrm{VT}$ & 151 & 43.0 & 9.72 & 827 & 51.6 & 9.64 & $<0.001$ \\
\hline SF & 150 & 47.9 & 11.2 & 832 & 51.6 & 8.91 & $<0.001$ \\
\hline $\mathrm{RE}$ & 148 & 47.1 & 11.8 & 827 & 51.9 & 8.43 & $<0.001$ \\
\hline $\mathrm{MH}$ & 150 & 45.4 & 9.68 & 826 & 51.2 & 9.08 & $<0.001$ \\
\hline PCS & 145 & 41.7 & 11.9 & 817 & 50.1 & 9.38 & $<0.001$ \\
\hline MCS & 145 & 42.7 & 9.83 & 817 & 50.5 & 9.27 & $<0.001$ \\
\hline RCS & 145 & 52.5 & 13.4 & 817 & 52.3 & 9.48 & 0.838 \\
\hline
\end{tabular}

SD: Standard Deviation; PF: Physical Functioning; RP: Role Physical; BP: Bodily Pain; GH: General Health; VT: Vitality; SF: Social Function; RE: Role Emotional; MH: Mental Health; PCS: Physical Component Summary; MCS: Mental Component Summary; RCS: Role Component Summary; ANCOVA was done with adjustment for age and gender.

Table 5 shows the results of multiple linear regression analysis with a forward stepwise approach to select independent variables for the three component summary scores. In this analysis, the independent variables included gender, age, and the site of pain. A lower PCS was independently correlated with CP at other sites ( $p<$ $0.001, \beta=-0.172)$, lumbar CP $(p<0.001, \beta=-0.132)$, age $(p<0.001, \beta=-0.154)$, knee CP $(p<0.001, \beta=$ $-0.115)$, and foot CP $(p=0.042, \beta=-0.065)$. Older age $(p<0.001, \beta=0.221)$ showed a significant positive correlation with MCS, while neck/shoulder CP $(p<0.01, \beta=-0.096)$, CP at other sites $(p<0.001, \beta=-0.108)$, knee CP ( $p<0.001, \beta=-0.109)$, upper limb CP $(p<0.01, \beta=-0.098)$, and lumbar CP $(p=0.022, \beta=-0.077)$ all showed a significant negative correlation with MCS. Chronic headache $(p=0.011, \beta=-0.082)$ only showed a significant correlation with a lower RCS (Table 5). 
Table 4. SF-36 component summary scores for subjects with or without chronic pain at different sites.

\begin{tabular}{|c|c|c|c|c|c|c|c|c|c|c|c|}
\hline \multirow{2}{*}{ Chronic pain site } & & \multirow{2}{*}{$\mathrm{N}$} & \multicolumn{3}{|c|}{ PCS } & \multicolumn{3}{|c|}{ MCS } & \multicolumn{3}{|c|}{ RCS } \\
\hline & & & Mean & SD & $P$ value & Mean & $\mathrm{SD}$ & $P$ value & Mean & $\mathrm{SD}$ & $P$ value \\
\hline \multirow[t]{2}{*}{ Head } & $(-)$ & 962 & 48.8 & 10.3 & 0.171 & 49.4 & 9.77 & 0.013 & 52.5 & 10.0 & 0.013 \\
\hline & $(+)$ & 10 & 45.1 & 10.5 & & 41.2 & 6.05 & & 44.3 & 19.9 & \\
\hline \multirow[t]{2}{*}{ Upper-limb } & $(-)$ & 955 & 48.9 & 10.3 & 0.050 & 49.5 & 9.74 & $<0.001$ & 52.4 & 10.0 & 0.365 \\
\hline & $(+)$ & 17 & 43.5 & 7.68 & & 40.4 & 7.23 & & 50.2 & 14.0 & \\
\hline \multirow[t]{2}{*}{ Neck-shoulder } & $(-)$ & 898 & 49.1 & 10.2 & $<0.001$ & 49.8 & 9.59 & $<0.001$ & 52.5 & 9.87 & 0.195 \\
\hline & $(+)$ & 70 & 44.0 & 10.8 & & 43.1 & 9.70 & & 50.9 & 13.0 & \\
\hline \multirow[t]{2}{*}{ Lumbar } & $(-)$ & 905 & 49.4 & 9.85 & $<0.001$ & 49.8 & 9.66 & $<0.001$ & 52.4 & 10.0 & 0.653 \\
\hline & $(+)$ & 61 & 40.9 & 12.4 & & 43.4 & 9.31 & & 51.9 & 12.5 & \\
\hline \multirow[t]{2}{*}{ Knee } & $(-)$ & 940 & 49.1 & 10.0 & $<0.001$ & 49.6 & 9.68 & $<0.001$ & 52.3 & 10.0 & 0.195 \\
\hline & $(+)$ & 30 & 39.2 & 12.5 & & 42.2 & 10.2 & & 54.7 & 13.0 & \\
\hline \multirow[t]{2}{*}{ Foot } & $(-)$ & 939 & 49.0 & 10.2 & $<0.001$ & 49.5 & 9.77 & $<0.01$ & 52.4 & 9.94 & 0.396 \\
\hline & $(+)$ & 31 & 40.7 & 11.0 & & 44.9 & 8.69 & & 50.9 & 14.9 & \\
\hline \multirow[t]{2}{*}{ Others } & $(-)$ & 946 & 49.1 & 10.0 & $<0.001$ & 49.6 & 9.66 & $<0.001$ & 52.4 & 10.0 & 0.835 \\
\hline & $(+)$ & 24 & 35.8 & 13.2 & & 40.8 & 9.90 & & 52.8 & 14.6 & \\
\hline
\end{tabular}

SD: Standard Deviation; PCS: Physical Component Summary; MCS: Mental Component Summary; RCS: Role Component Summary; Others include chest, abdomen, hip, and back pain. ANCOVA was performed with adjustment for age and gender.

Table 5. Multiple regression analysis of the relations between 3 component summary score and the pain site, gender.

\begin{tabular}{|c|c|c|c|c|c|c|c|c|}
\hline \multirow[b]{2}{*}{ Criterion } & \multirow[b]{2}{*}{ Variables } & \multirow[b]{2}{*}{ B } & \multirow[b]{2}{*}{ SE } & \multirow{2}{*}{$\begin{array}{c}\text { Beta } \\
\text { Standardized }\end{array}$} & \multirow[b]{2}{*}{$\mathrm{t}$} & \multirow[b]{2}{*}{$P$} & \multicolumn{2}{|c|}{ 95.0\% Confidence Interval for B } \\
\hline & & & & & & & $\begin{array}{l}\text { Lower } \\
\text { Bound }\end{array}$ & $\begin{array}{l}\text { Upper } \\
\text { Bound }\end{array}$ \\
\hline \multirow[t]{6}{*}{ PCS } & (Constant) & 61.02 & 2.25 & & 27.18 & $<0.001$ & 56.6 & 65.4 \\
\hline & Others & -11.29 & 2.03 & -0.172 & -5.57 & $<0.001$ & -15.3 & -7.31 \\
\hline & Lumbar & -5.55 & 1.35 & -0.132 & -4.12 & $<0.001$ & -8.19 & -2.90 \\
\hline & Age & -0.21 & 0.04 & -0.154 & -5.03 & $<0.001$ & -0.285 & -0.125 \\
\hline & Knee & -6.78 & 1.86 & -0.115 & -3.65 & $<0.001$ & -10.4 & -3.13 \\
\hline & Foot & -3.78 & 1.86 & -0.065 & -2.03 & 0.042 & -7.44 & -0.133 \\
\hline \multirow[t]{7}{*}{ MCS } & (Constant) & 34.94 & 2.15 & & 16.28 & $<0.001$ & 30.7 & 39.2 \\
\hline & Age & 0.28 & 0.04 & 0.221 & 7.23 & $<0.001$ & 0.205 & 0.357 \\
\hline & Neck-shoulder & -3.60 & 1.24 & -0.096 & -2.90 & $<0.01$ & -6.03 & -1.17 \\
\hline & Others & -6.72 & 1.93 & -0.108 & -3.48 & $<0.001$ & -10.5 & -2.93 \\
\hline & Knee & -6.11 & 1.74 & -0.109 & -3.51 & $<0.001$ & -9.52 & -2.70 \\
\hline & Upper-limb & -7.22 & 2.30 & -0.098 & -3.14 & $<0.01$ & -11.7 & -2.71 \\
\hline & Lumbar & -3.06 & 1.33 & -0.077 & -2.29 & 0.022 & -5.68 & -0.440 \\
\hline \multirow[t]{2}{*}{ RCS } & (Constant) & 52.47 & 0.33 & & 159.78 & $<0.001$ & 51.8 & 53.1 \\
\hline & Head & -8.16 & 3.22 & -0.082 & -2.54 & 0.011 & -14.5 & -1.84 \\
\hline
\end{tabular}

PCS; $\mathrm{R}^{2}=0.117$, Adjusted $\mathrm{R}^{2}=0.112$; MCS; $\mathrm{R}^{2}=0.119$, Adjusted $\mathrm{R}^{2}=0.113$; RCS; $\mathrm{R}^{2}=0.07$, Adjusted $\mathrm{R}^{2}=0.006$; SE: Standard Error; PCS: Physical Component Summary; MCS: Mental Component Summary; RCS: Role Component Summary; Others include chest, abdomen, hip, and back pain. Multiple linear regression analysis was performed with a forward stepwise approach, including gender, age, and site of pain. 


\section{Discussion}

In previous reports, prevalence rates of CP have varied [6]-[8], possibly due to bias related to different collection rates of questionnaires and selection bias. Participants in other studies were selected from internet volunteers and mail survey panels, so there were relatively low response rates, such as $72.2 \%$ for internet research [6] and $55 \%$ for the mail survey [7] In addition, there have been few investigations into the prevalence of CP or the relationship between CP and HRQoL involving an epidemiological survey of all residents in a region. One of our aim was to clarify more accurate prevalence rate of CP and its relationship with and HRQoL. In this study, we defined CP as an NRS score of more than 5 so that we could perform comparison with previous studies. Our results indicated that the prevalence of CP was $15.3 \%$ among men and $15.1 \%$ among women. In addition, CP was more prevalent in the lumbar and neck/shoulder regions of our working age subjects. According to previous population-based surveys, the prevalence of CP was 19\% in Europe and 13.6\% in Japan [5] [6]. Our survey method agreed with the previous population-based finding that the prevalence of $\mathrm{CP}$ is about $15.0 \%$, suggesting that our data were reliable.

The prevalence of chronic headache differs depending on the gender, age and geographic region [23]. Takeshima et al. examined the prevalence of headache in Daisen, a rural community in Japan, and reported that the prevalence of migraine was $2.3 \%$ in men and $9.1 \%$ in women [24]. An epidemiologic study performed by Sakai et al. revealed that the prevalence of migraine during the past year was $8.4 \%$ [25]. However, these studies assessed migraine and not chronic headache. Our study showed that the prevalence of chronic headache was $0.899 \%$ among men and $1.43 \%$ among women, suggest that there was no significant gender difference. Unfortunately, few data on chronic headache are available in Japan, different from migraine. Previous research has been performed in Spain [26], the Netherlands [27], the United States [28], and Korea [29], showing that the prevalence of chronic headache was $1.8 \%-4.2 \%$, with the lowest rate of $1.8 \%$ in Korea. These studies have suggested that the prevalence of chronic headache is lower in Asia than in western countries. Our results for a rural Japanese population support the concept that there is a lower prevalence of CP in Asia compared with Europe.

Suzukamo demonstrated that, among the 3 components of SF-36, RCS is strongly associated with the RP, SF, and RE subscales in specific social activities such as the number of times work, school, or housework missed for health-related reasons, and that this model was more appropriate than a two-component model for Japan and other Asian countries [22] [30]. It has been reported that social activities have independent health benefits [31], while the WHO has claimed that activity and participation involve factor structures in the international classification of functioning, disability, and health (ICF), in the same way as body function and structure [32].

We found that the influence of chronic headache on MCS and RCS, and not on PCS, whereas of musculoskeletal pain had a significant influence on PCS and MCS. Taken together with our identification of significant difference in PCS and MCS, but not in RCS between age categories, it seems that RCS is independent and distinct from either PCS or MCS in Japan.

It is noteworthy that our study demonstrated a relationship between chronic headache and RCS, because this has not been reported previously. Sakai et al. examined chronic tension headache and showed impairment of daily activities in $40.5 \%$ by this type of headache [33]. Bigal et al. reported that the impact of chronic headache is significantly greater than that of migraine, e.g. with regard to missing work and reducing productivity [11] [12]. In addition, Wang found lower SF-36 scores than normal in outpatients with headache and a lower score in those with chronic headache rather than migraine [34]. However, the influence of pain at other sites on HRQoL was not considered in previous studies. Holroyd et al. demonstrated that HRQoL scores were lower in chronic tension headache than in healthy controls, along with lower scores for back pain and arthritis [35]. In addition to our finding of a lower HRQoL in the present study population with chronic headache, we analyzed the effect of chronic headache after adjusting for pain at other sites which may have an impact on HRQoL. Therefore, our finding of a relationship between headache and RCS, which is supported by the above methods of analysis, provides convincing evidence for involvement of chronic headache in HRQoL (probably a different etiology from that at the other sites).

\section{Conclusion}

In conclusion, we demonstrated a relationship between RCS and chronic headache, but no relationships between RCS and musculoskeletal pain, while there was relationship between musculoskeletal pain and PCS or MCS. It suggested that RCS was independent component distinct from PCS and MCS in Japan. These results also sug- 
gested the influence of headache on HRQoL, probably because it had a different etiology from pain at other sites.

\section{Acknowledgements}

This study was supported by a Health Labour Sciences Research Grant for "Study on elucidation of the actual situation of intractable pain and development of countermeasures" (Principal Researcher: Takahiro Ushida, 2011-2012) and the fund for Priority Research Systems from Kanazawa University (No. 22,608) 2011-2012.

\section{Limitations}

There were some limitations of the present study. For example, it was a cross-sectional study with no clinical assessment. Causation cannot be inferred from a cross-sectional study, and prospective studies are needed to confirm causation. Also, we could not identify the etiology of pain, which would require objective investigations such as neurological examination or magnetic resonance imaging. Despite these limitations, we believe this study provides some useful insights for medical and public health practitioners because of the systematic method and high return rate of questionnaires.

\section{References}

[1] Merskey, H. and Bogduk, N. (1994) Classification of Chronic Pain. 2nd Edition, IASP Task Force on Taxonomy. IASP Press, Seattle. http://www.iasp-pain.org/Education/content.aspx?ItemNumber=1698

[2] Harstall, C. and Ospina, M. (2003) PAIN Clinical Updates 2003, XI, 7-9. http://iasp.files.cms-plus.com/Content/ContentFolders/Publications2/PainClinicalUpdates/Archives/PCU03-2__1390265 045864_38.pdf

[3] Gureje, O., Von Korff, M., Simon, G.E. and Gater, R. (1998) Persistent Pain and Well-Being. Jama, $280,147$. http://dx.doi.org/10.1001/jama.280.2.147

[4] Dawson, J., Linsell, L., Zondervan, K., Rose, P., Carr, A., Randall, T., et al. (2005) Impact of Persistent Hip or Knee Pain on Overall Health Status in Elderly People: A Longitudinal Population Study. Arthritis Rheum, 53, 368-374. http://dx.doi.org/10.1002/art.21180

[5] Breivik, H., Collett, B., Ventafridda, V., Cohen, R. and Gallacher, D. (2006) Survey of Chronic Pain in Europe: Prevalence, Impact on Daily Life, and Treatment. European Journal of Pain, 10, 287-333. http://dx.doi.org/10.1016/j.ejpain.2005.06.009

[6] Hattori, S. (2006) The Prevalence of Chronic Pain in Japan. Nihon Yakurigaku Zasshi, 127, 176-180. http://dx.doi.org/10.1254/fpj.127.176

[7] Nakamura, M., Nishiwaki, Y., Ushida, T. and Toyama, Y. (2011) Prevalence and Characteristics of Chronic Musculoskeletal Pain in Japan. Journal of Orthopaedic Science, 16, 424-432. http://dx.doi.org/10.1007/s00776-011-0102-y

[8] Matsudaira, K., Takeshita, K., Kunogi, J., Yamazaki, T., Hara, N., Yamada, H., et al. (2011) Prevalence and Characteristics of Chronic Pain in the General Japanese Population. Pain Clin, 32, 1345-1356.

[9] Suka, M. and Yoshida, K. (2009) The National Burden of Musculoskeletal Pain in Japan: Projections to the Year 2055. Questionnaire Survey on Musculoskeletal Pain, 25, 313-319.

[10] Nakamura, M., Nishiwaki, Y., Ushida, T. and Toyama, Y. (2014) Prevalence and Characteristics of Chronic Musculoskeletal Pain in Japan: A Second Survey of People with or without Chronic Pain. Journal of Orthopaedic Science, 19, 339-350. http://dx.doi.org/10.1007/s00776-013-0525-8

[11] Bigal, M.E., Rapoport, A.M., Lipton, R.B., Tepper, S.J. and Sheftell, F.D. (2003) Assessment of Migraine Disability Using the Migraine Disability Assessment (MIDAS) Questionnaire: A Comparison of Chronic Migraine with Episodic Migraine. Headache, 43, 336-342. http://dx.doi.org/10.1046/j.1526-4610.2003.03068.x

[12] Bigal, M.E., Serrano, D., Reed, M. and Lipton, R.B. (2008) Chronic Migraine in the Population: Burden, Diagnosis, and Satisfaction with Treatment. Neurology, 71, 559-566. http://dx.doi.org/10.1212/01.wnl.0000323925.29520.e7

[13] Buse, D.C., Manack, A., Serrano, D., Turkel, C. and Lipton, R.B. (2010) Sociodemographic and Comorbidity Profiles of Chronic Migraine and Episodic Migraine Sufferers. Journal of Neurology, Neurosurgery \& Psychiatry, 81, 428-432. http://dx.doi.org/10.1136/jnnp.2009.192492

[14] Fukuhara, S., Bito, S., Green, J., Hsiao, A. and Kurokawa, K. (1998) Translation, Adaptation, and Validation of the SF-36 Health Survey for Use in Japan. Journal of Clinical Epidemiology, 51, 1037-1044.

http://dx.doi.org/10.1016/S0895-4356(98)00095-X 
[15] Fukuhara, S. and Yoshimi, S. (2011) Manual of SF-36v2 Japanese Version. Institute for Health Outcome and Process Evaluation Research.

[16] Fukuhara, S., Ware, J.E., Kosinski, M., Wada, S. and Gandek, B. (1998) Psychometric and Clinical Tests of Validity of the Japanese SF-36 Health Survey. Journal of Clinical Epidemiology, 51, 1045-1053. http://dx.doi.org/10.1016/S0895-4356(98)00095-X

[17] Li, L., Wang, H.M. and Shen, Y. (2003) Chinese SF-36 Health Survey: Translation, Cultural Adaptation, Validation, and Normalisation. Journal of Epidemiology \& Community Health, 57, 259-263. http://dx.doi.org/10.1136/jech.57.4.259

[18] Yu, J., Coons, S.J., Draugalis, J.R., Ren, X.S. and Hays, R.D. (2003) Equivalence of Chinese and US-English Versions of the SF-36 Health Survey. Quality of Life Research, 12, 449-457. http://dx.doi.org/10.1023/A:1023446110727

[19] Fuh, J.L., Wang, S.J., Lu, S.R., Juang, K.D., Lee, S.J. (2000) Psychometric Evaluation of a Chinese (Taiwanese) Version of the SF-36 Health Survey amongst Middle-Aged Women from a Rural Community. Quality of Life Research, 9, 675-683. http://dx.doi.org/10.1023/A:1008993821633

[20] Thumboo, J., Fong, K.Y., Machin, D., Chan, S.P., Leon, K.H., Feng, P.H., et al. (2001) A Community-Based Study of Scaling Assumptions and Construct Validity of the English (UK) and Chinese (HK) SF-36 in Singapore. Quality of Life Research, 10, 175-188. http://dx.doi.org/10.1023/A:1016701514299

[21] Ware Jr., J.E., Kosinski, M., Bayliss, M.S., McHorney, C.A., Rogers, W.H. and Raczek, A. (1995) Comparison of Methods for the Scoring and Statistical Analysis of SF-36 Health Profile and Summary Measures: Summary of Results from the Medical Outcomes Study. Medical Care, 33, AS264-AS279.

[22] Suzukamo, Y., Fukuhara, S., Green, J., Kosinski, M., Gandek, B. and Ware, J.E. (2011) Validation Testing of a Three-Component Model of Short Form-36 Scores. Journal of Clinical Epidemiology, 64, 301-308. http://dx.doi.org/10.1016/j.jclinepi.2010.04.017

[23] Jensen, R. and Stovner, L.J. (2008) Epidemiology and Comorbidity of Headache. The Lancet Neurology, 7, $354-361$. http://dx.doi.org/10.1016/S1474-4422(08)70062-0

[24] Takeshima, T., Ishizaki, K., Fukuhara, Y., Ijiri, T., Kusumi, M., Wakutani, Y., et al. (2004) Population-Based Door-to-Door Survey of Migraine in Japan: The Daisen Study. Headache, 44, 8-19. http://dx.doi.org/10.1111/j.1526-4610.2004.04004.x

[25] Sakai, F. and Igarashi, H. (1997) Prevalence of Migraine in Japan: A Nationwide Survey. Cephalalgia, 17, 15-22. http://dx.doi.org/10.1046/j.1468-2982.1997.1701015.x

[26] Castillo, J., Mu-oz, P., Guitera, V. and Pascual, J. (1999) Kaplan Award 1998. Epidemiology of Chronic Daily Headache in the General Population. Headache, 39, 190-196. http://dx.doi.org/10.1046/j.1526-4610.1999.3903190.x

[27] Russell, M.B. (2005) Tension-Type Headache in 40-Year-Olds: A Danish Population-Based Sample of 4000. The Journal of Headache and Pain, 6, 441-447. http://dx.doi.org/10.1007/s10194-005-0253-3

[28] Scher, A.I., Stewart, W.F., Liberman, J. and Lipton, R.B. (1998) Wolff Award 1998 Prevalence of Frequent Headache in a Population Sample. Headache, 38, 497-506. http://dx.doi.org/10.1046/j.1526-4610.1998.3807497.x

[29] Park, J., Moon, H., Kim, J., Lee, K. and Chu, M.K. (2014) Chronic Daily Headache in Korea: Prevalence, Clinical Characteristics, Medical Consultation and Management. Journal of Clinical Neurology, 10, 236-243. http://dx.doi.org/10.3988/jcn.2014.10.3.236

[30] Nezu, S., Okamoto, N., Morikawa, M., Saeki, K., Obayashi, K., Tomioka, K., et al. (2014) Health-Related Quality of Life (HRQOL) Decreases Independently of Chronic Conditions and Geriatric Syndromes in Older Adults with Diabetes: The Fujiwara-Kyo Study. Journal of Epidemiology, 24, 259-266. http://dx.doi.org/10.2188/jea.JE20130131

[31] Glass, T.A., de Leon, C.M., Marottoli, R.A. and Berkman, L.F. (1999) Population Based Study of Social and Productive Activities as Predictors of Survival among Elderly Americans. BMJ, 319, 478-483. http://dx.doi.org/10.1136/bmj.319.7208.478

[32] World Health Organization (2001) International Classification of Functioning, Disability and Health (ICF). Geneva. http://www.who.int/classifications/icf/en/

[33] Sakai, F. and Igarashi, H. (1997) Prevalence of Migraine in Japan: A Nationwide Survey. Cephalalgia, 17, 15-22. http://dx.doi.org/10.1046/j.1468-2982.1997.1701015.x

[34] Wang, S.J., Fuh, J.L., Lu, S.R. and Juang, K.D. (2001) Quality of Life Differs among Headache Diagnoses: Analysis of SF-36 Survey in 901 Headache Patients. Pain, 89, 285-292. http://dx.doi.org/10.1016/S0304-3959(00)00380-8

[35] Holroyd, K.A., Stensland, M., Lipchik, G.L., Hill, K.R., O’Donnell, F.S. and Cordingley, G. (2000) Psychosocial Correlates and Impact of Chronic Tension-Type Headaches. Headache, 40, 3-16. http://dx.doi.org/10.1046/j.1526-4610.2000.00001.x 